Thorax, 1978, 33, 528-529

\title{
An original technique for surgical stabilisation of traumatic flail chest
}

\author{
V BELTRAMI, G MARTINELLI, P GIANSANTE, AND K GENTILE
}

From the Istituto di Patologia Chirurgica dell'Universita, Ospedali Riuniti "SS Annunziata," Chieti, Italy

Beltrami, V, Martinelli, G, Giansante, P, and Gentile, K (1978). Thorax, 33, 528-529. An original technique for surgical stabilisation of traumatic flail chest. The treatment of chest wall injuries with severe paradoxical movement remains controversial. Intermittent positive-pressure respiration may be appropriate, but in some, especially those requiring exploratory thoracotomy for a visceral lesion, surgical fixation is desirable. We present a simple method using two or three stainless Kirschner wires placed in the chest wall. Results in five cases have been good.

The treatment of severe chest wall injury with paradoxical respiration is primarily directed to stabilising the chest wall. If the area is small in size this may be done with strapping or sandbags. More extensive areas can be handled by traction to the unstable part of the chest wall by wires, towel clips, or other means (Beltrami and Intonti, 1967; Naclerio, 1969). Intermittent positivepressure respiration (IPPR) may be appropriate but should not be used for long-term chest wall stabilisation (Naclerio, 1969).

In the past few years various methods of fixation (Eschapasse and Gaillard, 1973; SanchezLloret, 1974; Paris et al, 1975) have been suggested using curved struts, intramedullary nails, wires, staples, or bone grafts (Naclerio, 1969; Guernelli et al, 1971). No one method is applicable to all cases.

\section{Method}

During the past three years we have used a simple method of fixation when exploratory thoracotomy was indicated. At the completion of the thoracotomy two or three stainless Kirschner wires are inserted into the chest wall from below, passing outside intact ribs, inside the flail segment, and then outside intact ribs above (see figs 1 and 2). The wires are easily removed 20 to 30 days later when the chest wall has consolidated (fig 3 ).

From 1973 to 1976,127 patients with closed chest injuries were admitted to our department. Nine had a flail chest. Three were treated by IPPR, one by intramedullary nailing of the ribs, and five by Kirschner wire fixation. All cases treated surgically had a good result.

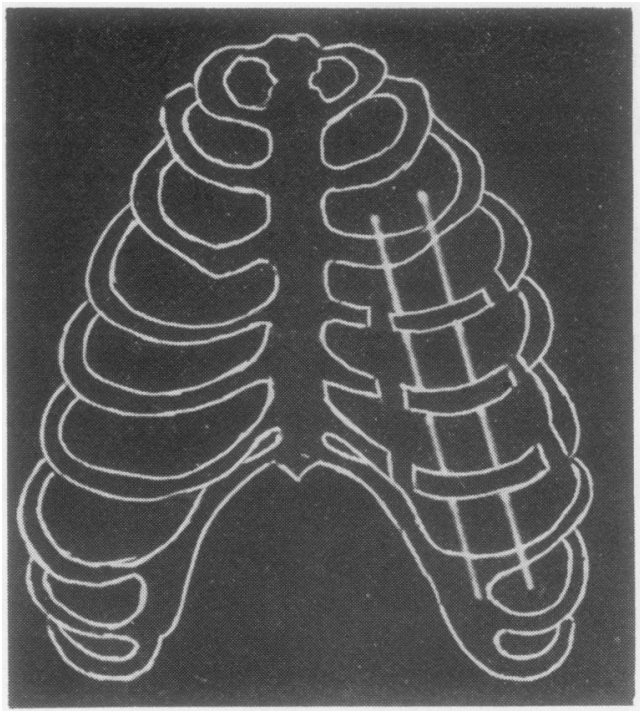

Fig 1 Diagram of technique of chest wall fixation with Kirschner wires.

\section{References}

Beltrami, V, and Intonti, F (1967). Chirurgia toracica d'urgenza. Cappelli, Bologna.

Eschapasse, H, and Gaillard, J (1973). Volets thoraci $\frac{T}{\circ}$ ques. Principes de traitement. Annales de Chirurgie $\frac{\stackrel{\odot}{\oplus}}{\circ}$ Thoracique et Cardiovasculaire, 12, 1-13.

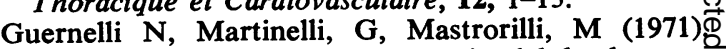
Nostro orientamento nella terapia del lembo parō ietale mobile anteriore. Archivio Società Italiană Chirurgia, $73^{\circ}$ Congresso, Napoli. 


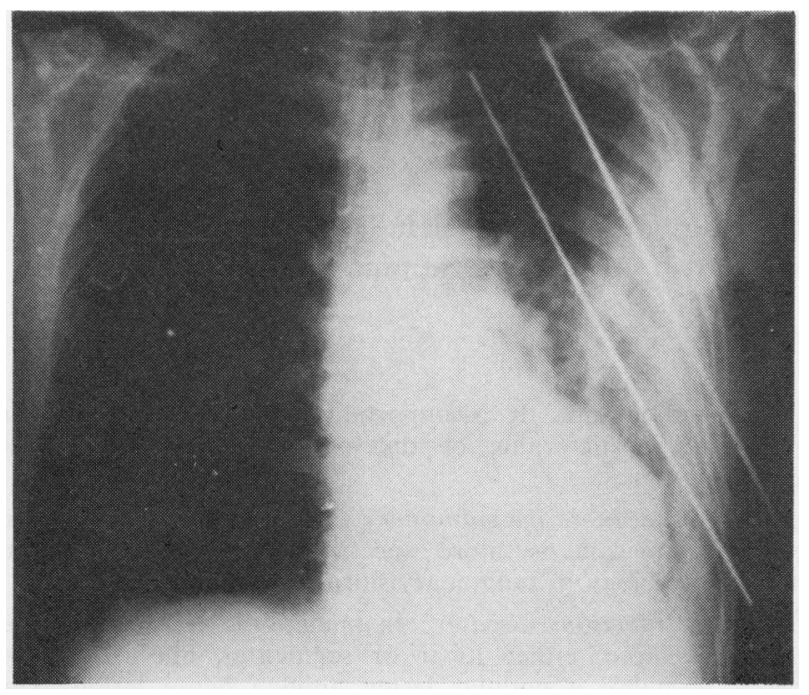

Fig 2 Radiograph of left anterolateral flail chest in man of 57 treated with Kirschner wire fixation.

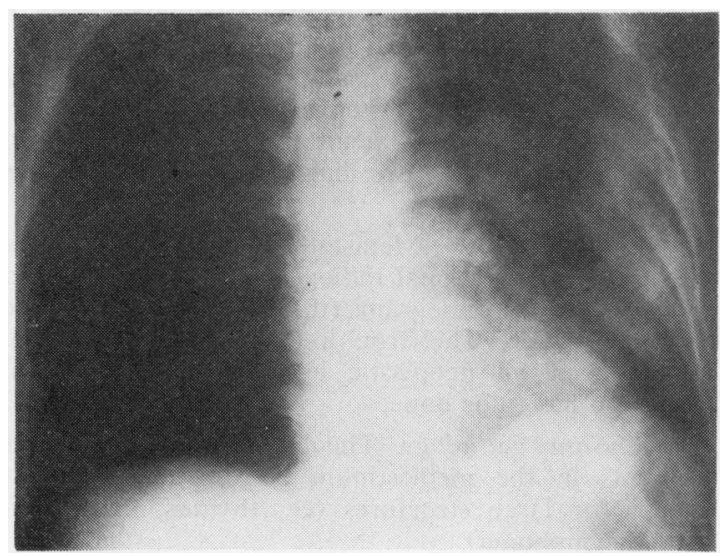

Fig 3 Chest radiograph of same patient, 45 days later.
Naclerio, E A (1969). Surgical Diseases of the Chest, collected papers. T Printing, Hoboken (New Jersey).

Paris, F, Tarazona, V, Blasco, E, Canto, A, Casillas, M, Pastor, J, Paris, M, and Montero, R (1975). Surgical stabilisation of traumatic flail chest. Thorax, 30, 527.

Sanchez-Lloret, J (1974). Osteosintesis costal mediante placa extraperiostica. Revista Quirurgica Espanola, 1, 69 .

Requests for reprints to: Professor V Beltrami, Istituto di Patologia Chirurgica dell'Universita, Ospedali Riuniti "SS Annunziata," Chieti, Italy. 